\title{
USING CA-MARKOV MODEL TO MODEL THE SPATIOTEMPORAL CHANGE OF LAND USE/COVER IN FUXIAN LAKE FOR DECISION SUPPORT
}

\author{
S.H. Li ${ }^{\text {a,b }}$, B.X. Jin ${ }^{\text {b,* }}$, X.Y. Wei ${ }^{\text {b,c }}$, Y.Y. Jiang ${ }^{\text {d }}$, J.L.Wang ${ }^{\text {a }}$

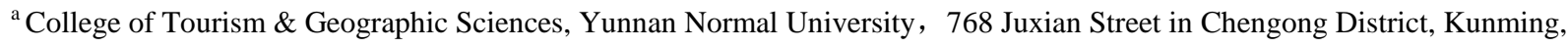 \\ Yunnan, China-lsh8010@163.com, wang_jinliang@hotmail.com \\ b Yunnan Provincial Geomatics Centre, 404 West Ring Road, Kunming, Yunnan, China- (1sh8010, jinbx163)@163.com, \\ 19423221@qq.com \\ ${ }^{\mathrm{c}}$ College of Geographic Sciences, Nanjing Normal University, No.1,Wenyuan Road, Xianlin University District,Nanjing,China- \\ 19423221@qq.com \\ ${ }^{\mathrm{d}}$ Center for Intelligent Spatial Computing, George Mason University, 4400 University Dr., Fairfax, VA, USA-yjiang8@ gmu.edu
}

KEY WORDS: LUCC, CA-Markov Model, Dynamic Modelling, Optimized Modelling Scale Combination, Fuxian Lake Watershed

\begin{abstract}
:
Spatiotemporal modelling of land use/cover change (LUCC) has become increasingly important in recent years, especially for environmental change and regional planning. There have been many approaches and software packages for modelling LUCC, but developing a model for a specific region is still a difficult task, because it requires large volume of data input and elaborate model adjustment. Fuxian Lake watershed is one of the most important ecological protection area in China and located in southeast of Kunming city, Yunnan province. In this paper, the CA-Markov model is used to analyse the spatiotemporal LUCC and project its course into the future. Specifically, the model uses high resolution remote sensing images of 2006 and 2009 as input data, and then makes prediction for 2014. A quantitative comparison with remote sensing images of 2014 suggests an overall accuracy of $88 \%$. This spatiotemporal modelling method is expected to facilitate the research of many land cover and use applications modelling.
\end{abstract}

\section{INTRODUCTION}

Since LUCC has direct and indirect impact on a number of factors of ecological environment, as well as the regional and global sustainable development, the land change modelling has attracted increasing attention in the context global climate change (Li, 1996; Wijesekara et al., 2012). The continuous evolution and transformation of land surface has resulted in serious consequence to the physical system at multiple scales, and raised a number of change in the ecological processes, such as surface runoff, soil erosion and agricultural non-point source pollution (Wijesekara et al., 2012; Li et al., 2010; Ouyang et al., 2010). Analysing the characteristics of the LUCC, exploring changes at different spatiotemporal scale and predicting future scenarios contribute is of significance for providing decisionmaking basis for the regional ecological protection and sustainable development.

At present, mainstream LUCC models include modelling system dynamics model, Clue-S model, Multi-agent model and Markov model (Duan et al., 2004; Wang et al., 2012; Xiao et al., 2012; Yang et al., 2007; Qin et al., 2009; Hou et al., 2004). None of them are perfect. The efficiency of Clue-S model is not satisfactory and it has to rely on results from other auxiliary software. The Markov model can quantitatively predict the dynamic changes of landscape pattern, while it can't deal with the spatial pattern of landscape change (Balzter et al., 1998). In contrast, the cellular automata (CA) model is able to predict the spatial distribution of the landscape pattern, but it cannot predict the change in time dimension (Cheng et al., 2013). In this context, researchers have turned to integrating different methods to study dynamic modelling of LUCC (Qin et al., 2009).

Among them, CA-Markov that combines CA with Markov integrates the advantages of both methods. Since it is able to model the spatiotemporal dynamic change of land cover change, the model is widely applied in many scientific communities. Balzter et al. (1998) simulated the spatial dynamic change process of vegetation in Giessen University in German from 1993 to1996. Liu and Andersson (2004) simulated the evolution of the settlement pattern of two cities. Jenerette and Wu (2001) analysed and simulated land use change situation of Phoenix district in Arizona in the United States, the results show that land use change is closely related to the urban expansion and population increase in the past 83 years.

Although the research of using CA model to simulate LUCC mainly focuses on applied research, the sensitivity of the model with different parameters is also needed to be analysed. Berling and $\mathrm{Wu}(2004)$ used multi-scale testing method to calibrate and validate the model of Phoenix town development, and it is concluded that the higher spatial resolution of the input data was, the higher accuracy of modelling using the CA model would be. Menard and Marceau (2005) studied the sensitivity of CA model between the neighbour structure and the spatial resolution in 2005. Mondal et al. (2012) revealed that the $5 \times 5$

* Corresponding author 
contiguity filters produced most geospatially distributed effective results based on a comparison with different contiguity filters i.e. $3 \times 3,5 \times 5$ and $7 \times 7$ contiguity filters. Liu et al. (2004) explored impact from the time interval the on urban development model based on CA. Verda et al. (2006) discussed the sensitivity of the neighbour structure to the model.

Taking urban growth model of Changsha city as an example, Yin et al. (2008) studied the problem of the modelling scale using CA model, and presented that city growth model with CA has higher modelling accuracy only in certain scale, and the model has a certain sensitivity to the scale( $\mathrm{Li}$ and Liu, 2007). $\mathrm{Ke}$ et al. (2010) has looked into the influence of cellular size to cellular automata model. The research mentioned above is focused on the sensitivity of a single scale, such as cellular size and scope of neighbourhood. A lot of work about the scale's relationship with itself and the optimal combination of various scale for higher modelling precision remained to be done.

To address these challenges, taking Fuxian Lake watershed as study area, the relationship between cellular size and neighbourhood range is analysed. In addition, its impact on prediction accuracy in a predetermined time interval is discussed.

\section{DATA AND STUDY AREA}

\subsection{Study Area}

Fuxian Lake is located in the centre of Yunnan province, and it is the second deepest fresh water lake in China. It is not only an important resource for the sustainable development of social economy in the Yunnan province, but also supply for the strategic water resources for pan-pearl river delta regional.

Because of environmental change and human activities, the land cover around Fuxian lake watershed has been changed dramatically and increasing attention has been paid to the land change modelling of this area. Modelling accurate is pivotal because the results can serve as the basic data and scientific evidence to the sustainable development of Fuxian watershed's ecosystem and the improvement of the water quality. In the meanwhile, it can also provide the macro decision-making support to the government and the related departments on the protection of the vegetation, and the development and management of tourism resources in Fuxian lake watershed.

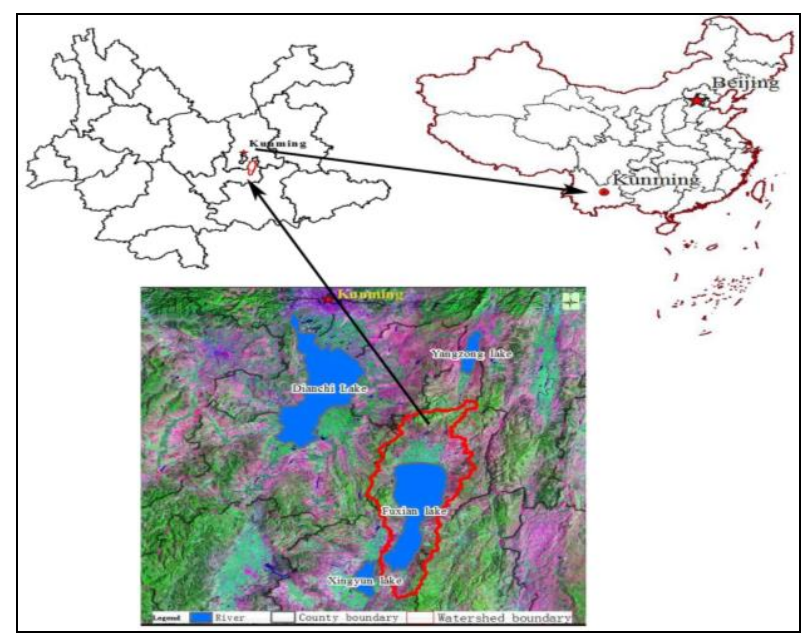

Figure 1. Location of study area

\subsection{Data}

We used high resolution remote sensing images of SPOT-5, QuickBird, and WorldView-2 in the study area. Images of 2006 and 2009 are used for model establishment, and image of 2014 is used for validation. Details about data is shown Table 1. Other geographic data such as DEM with $10 \mathrm{~m}$ grid size, 1:10000 digital vector data (roads, drainage, transportation, residents) renewed in 2014 and the planning data for Fuxian Lake protection and development from Administration of Fuxian Lake protection are also selected.

\begin{tabular}{cccccc}
\hline Satellite & Data & $\begin{array}{c}\text { Resol } \\
\text { ution }\end{array}$ & $\begin{array}{c}\text { Product } \\
\text { Level }\end{array}$ & $\begin{array}{c}\text { Cloud } \\
\text { cover } \\
(\%)\end{array}$ & Source \\
\hline SPOT-5 & $\begin{array}{c}2006- \\
01-30\end{array}$ & $2.5 \mathrm{~m}$ & DOM & 0.012 & Purchased \\
& & & & \\
Quick- & $2009-$ & $0.61 \mathrm{~m}$ & DOM & 0.022 & Purchased \\
Bird & $01-20$ & & & & \\
World- & $2014-$ & $0.5 \mathrm{~m}$ & DOM & 0.031 & Purchased \\
View-2 & $01-18$ & & & & \\
\hline
\end{tabular}

Table 1. Details of satellite data

After classification, all pixels are classified into ten classes including Cultivated Land (CL), Woodland(WL), Garden(G), Grass Land(GL), Building Region(BR), Road(R), Structure(S), Artificial Piling and Digging Land(APDL), Water(W), Desert and Bare surface(DB). The aspect and slope data is derived from 10m grid DEM The suitability map which represents the suitability maps for each land-use classes of study area is generated by considering multiple factors such as DEM, roads, drainage, transportation, residents and the census data such as administrative boundary, core area, and protection area of Fuxian Lake.

\subsection{Methodology}

2.3.1 CA-Markov Model: The Markov model can quantitatively predict the dynamic changes of landscape pattern, while it is not good at dealing with the spatial pattern of landscape change. On the other hand, Cellular Automata (CA) has the ability to predict any transition among any number of categories (GIL et al., 2005). Combining the advantages of Cellular Automata theory and the space layout forecast of Markov theory, CA-Markov model performs better in modelling land cover change in both time and spatial dimension. At present, IDRISI software is one of the best platforms to conduct CA-Markov model, which is developed by Clark Labs in the U.S.

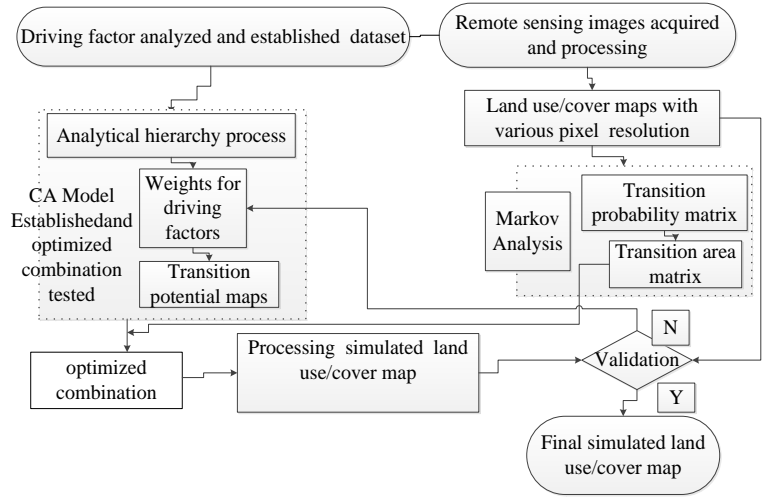


Figure 2. A flow chart of modeling process

We explored the trends and driving forces of LUCC in the Fuxian lake watershed, by using socioeconomic and census data of the Fuxian lake watershed. ArcGIS v10.1 and IDRISI, Andes, V15.0 software are used in this research to generate land cover transition matrix and transition probability of Fuxian lake watershed in 2006 and 2014. Land cover pattern in 2014 based on different scale combination by using CA-Markov module. Compared with the land cover truth in 2014, the precision of the modelling has been tested and the optimal scale is established. Land use grid map, suitability atlas and the matrix of land cover types are input into CA - Markov module to build model which is then used to predict the land cover pattern in 2022. Flowchart of the modelling process is shown in Figure 2. It consists of the following steps:

1) Establishing transition matrix. Overlay the land cover maps of 2006 and 2014 (Figure 3). Set the time interval between two maps to be nine years, the ratio error to 0.15 , and calculate the transition probability matrix of land-use (Table 2) and the transformation matrix of land change.

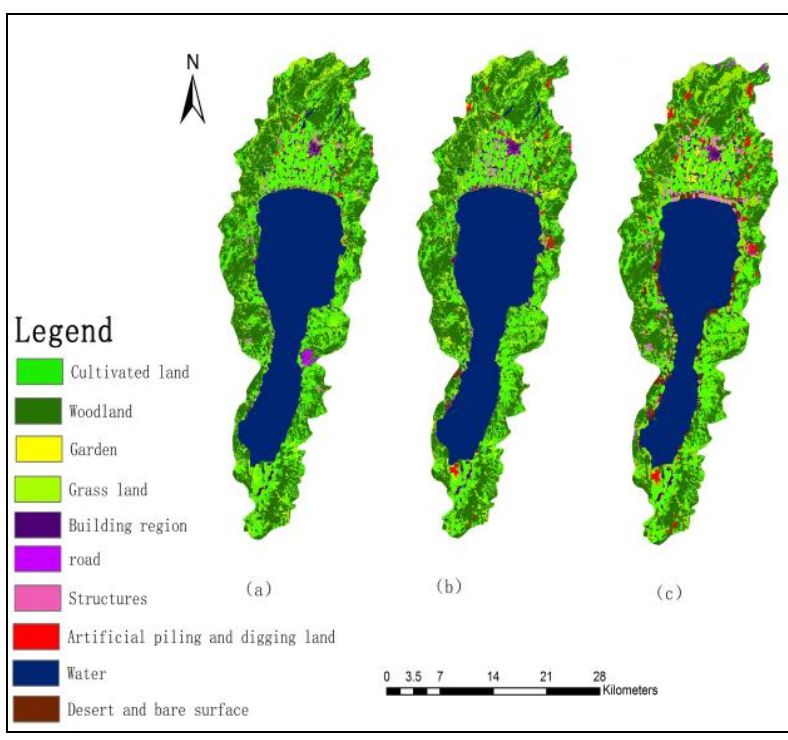

Figure 3. The map of land use type ((a) 2006, (b) 2014, (c) 2022

\begin{tabular}{lllllllllll}
\hline \multicolumn{1}{r}{2014} & CL & G & WL & GL & BR & R & S & APDL & DBS & W \\
2006 & & & & & & & & & & \\
\hline CL & 73.87 & 1.83 & 8.05 & 7.76 & 1.51 & 0.78 & 3.58 & 2.11 & 0.19 & 0.32 \\
G & 8.57 & 70.98 & 5.4 & 2.95 & 7.11 & 0.58 & 1.24 & 2.07 & 0.61 & 0.5 \\
WL & 6.62 & 0.17 & 79.79 & 8.49 & 0.47 & 0.57 & 0.32 & 2.19 & 1.3 & 0.08 \\
GL & 8.08 & 0.29 & 13.77 & 71.84 & 0.75 & 0.39 & 0.67 & 3.48 & 0.25 & 0.48 \\
BR & 2.26 & 0.44 & 6.12 & 1.35 & 82.44 & 1.19 & 3.73 & 1.95 & 0.4 & 0.12 \\
R & 0.68 & 0.03 & 1.73 & 1.03 & 0.48 & 95.11 & 0.26 & 0.23 & 0.42 & 0.03 \\
S & 3.19 & 0.15 & 7.55 & 0.84 & 0.56 & 0.19 & 86.55 & 0.65 & 0.28 & 0.04 \\
APDL & 9.32 & 3.78 & 8.56 & 13.05 & 6.65 & 4.23 & 3.07 & 50.49 & 0 & 0.86 \\
DBS & 4.27 & 0.09 & 28.79 & 13.44 & 0.82 & 0.73 & 1.91 & 1.54 & 43.86 & 4.54 \\
W & 4.43 & 0.05 & 1.5 & 3.68 & 0.22 & 0.14 & 1.06 & 0.26 & 4.58 & 84.08 \\
\hline
\end{tabular}

Table 2. Transition probability of land use type between 2006 and 2014（unit: /\%)

From Table 2, we can see that desert and bare surface, artificial piling and digging land, garden land, grassland, woodland transition probability is higher, roads and structures.
Water and building transition probability is lower between 2006 and 2014.

\begin{tabular}{|c|c|c|c|c|c|c|c|c|c|c|}
\hline $\begin{array}{l}\text { Types } \\
\text { years }\end{array}$ & $\mathrm{CL}$ & G & WL & GL & $\mathrm{BR}$ & $\mathrm{R}$ & $S$ & APDL & DBS & $\mathrm{W}$ \\
\hline 2006 & 153.79 & 3.27 & 219.84 & 49.26 & 13.21 & 8.57 & 4.18 & 2.18 & 1.15 & 219.83 \\
\hline 2014 & 143.75 & 5.35 & 217.69 & 54.42 & 14.94 & 7.41 & 5.81 & 5.53 & 2.42 & 217.96 \\
\hline 2022 & 149.07 & 7.52 & 199.91 & 73.63 & 15.85 & 6.99 & 11.50 & 10.33 & 13.82 & 186.82 \\
\hline Area & 5.32 & 2.17 & -17.79 & 19.22 & 0.91 & -0.42 & 5.69 & 4.80 & 11.39 & -31.14 \\
\hline $\begin{array}{l}\text { Changes } \\
2014-2022\end{array}$ & & & & & & & & & & \\
\hline $\begin{array}{l}\text { Area } \\
\text { Changes } \\
\text { 2006-2022 }\end{array}$ & -4.72 & 4.25 & -19.93 & 24.37 & 2.64 & -1.58 & 7.33 & 8.15 & 12.67 & -33.01 \\
\hline
\end{tabular}

Table 3. The area statistics of land use type (Unit: /square kilometers)

From Table 3, we can see that the variation of water's area is the largest, the grassland, forest land, desert and the bare land are changed a little. Among them, water, woodland, desert and bare surface are showed a decreasing trend, and the desert and bare surface increased.

2) Setting the Cellular size. Define each pixel in raster data as 1 unit. Considering spatial resolution, the minimum area of each type in referencing data (2014), and the computing time, the cellular size is divided into a number of sizes including $1 \mathrm{~m} \mathrm{x}$ $1 \mathrm{~m}, 5 \mathrm{~m} \times 5 \mathrm{~m}, 10 \mathrm{~m} \times 10 \mathrm{~m}, 15 \mathrm{~m} \times 15 \mathrm{~m}, 20 \mathrm{~m} \times 20 \mathrm{~m}, 25 \mathrm{~m} \times 25 \mathrm{~m}$, and $30 \mathrm{~m} \times 30 \mathrm{~m}$.

3) Defining the CA filter. To define the neighbor with the 
default $\mathrm{N} \times \mathrm{N}$ filter, namely $\mathrm{N} \times \mathrm{N}$ unit has a significant influence on their surrounding unit. Filter is respectively set as $3 \times 3,5 \times 5,7 \times 7,9 \times 9$, and $11 \times 11$.

4) Creating the suitability map. The transition rules are set up using a multi-criteria evaluation (MCE) and fuzzy membership function suitability maps for each simulated land cover class (Eastman, 2006). The core of CA is the evolution rules which are defined by MCE and the suitable map generated by COLLETION EDIT module in the IDRISI software. And then we can know the cellular status in the next time. In order to improve ecological environment and promote socioeconomic sustainable development in the watershed, suitability map (Figure 4) are created by following the constraints such as distance, the current land use and combined the impacts of all those seven factors(towns, waters, roads, gradient, slope, construction land and limit development zone) on the land use types. Those factors were then unified and quantified one suitability map based on certain weights, and map value was standardized to $[0,255]$ as the CA transition parameters, with higher values indicating greater suitability. Figure 4 shows the suitability maps for each land-use classes of study area.

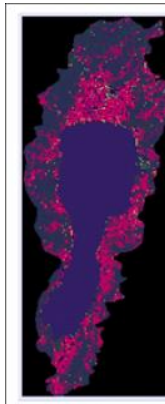

(a)

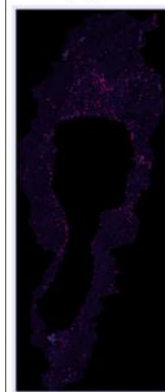

(f)
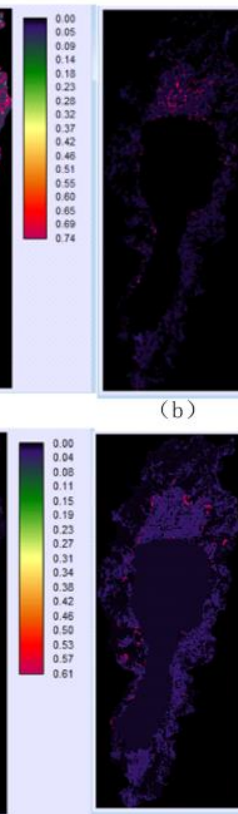

( $\mathrm{g}$ )

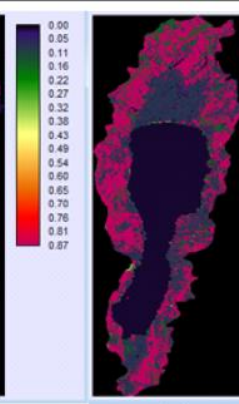

(c)

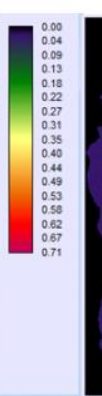

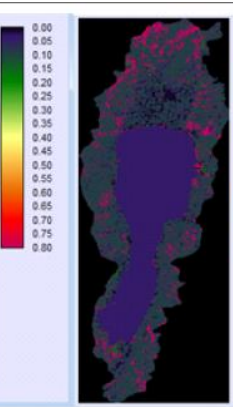

(d)

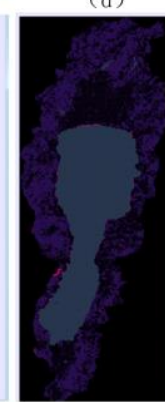

(i)

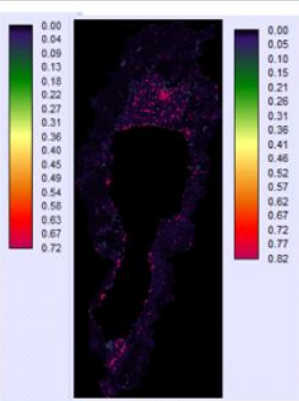

(e)

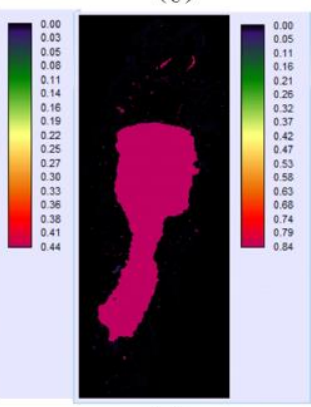

(j)

(a) Cultivated land (b ) Garden (c)Woodland (d) Grass land (e) Building region (f) Road (g) Structures (h) Artificial piling and digging land (i) Desert and bare surface (j) Water

Figure 4. Suitability map used to predict future LUCC

5) CA-Markov sensitivity test. The effects on modelling accuracy for different sizes of units and the scope of neighborhood are analyzed in the definite transformation rules and time interval. The sensitivity is analyzed by comparing the Kappa value of different modelling combination (Figure 5).

2.3.2 Analysis Results of LUCC Modelling in the Watershed: Most researchers use Kappa coefficient to evaluate modelling modeling accuracy of CA-Markov model. It quantitatively reflects the modelling accuracy. For appropriate validation, the map of recent real LUCC used for validation should not be used in calibration (Pontius and Schneider, 2001).

In order to validatethe reliability of KAPPA consistency coefficient to evaluation results, KAPPA value and Cramer's V value are obtained by comparing modelling map and the ground truth, and the result is shown in Figure 5..

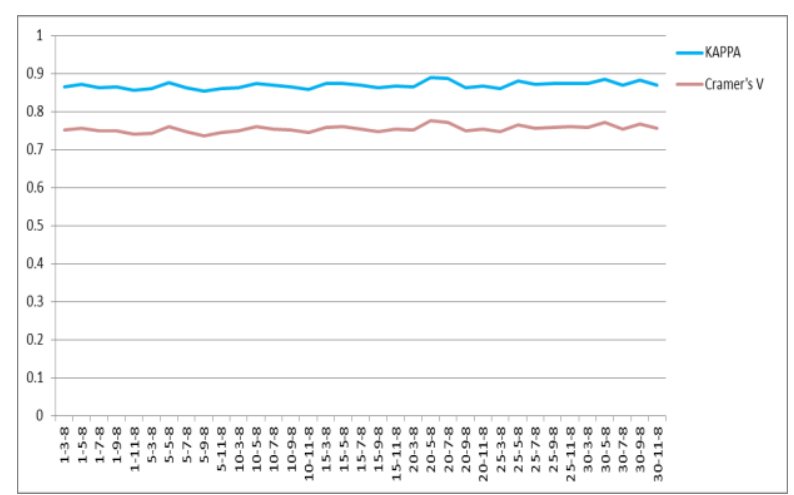

Figure 5. The graph of KAPPA and Cramer 's V value

In the graph, the combination 30-9-8 means: cellular size is 30 $\mathrm{m}$, neighborhood is $9 \times 9$, and time interval is 8 years. We can see from the graph as follows:

1) KAPPA value and Cramer's V curve trend is consistent, which proves that you can use the KAPPA consistency coefficient to evaluate the result of the modelling.

2) There is not obvious linear relationship between the cellular 
size and KAPPA value, and the KAPPA value does not change with the increase of cellular size. The maximum KAPPA value is obtained in the combination of $20 \mathrm{~m}$ cellular size, $5 \times 5$ neighborhood.

3) Time interval has different effects on the modelling based on the different cellular size and neighborhood scale. The combination of 20-5-8 has obtained the highest modelling accuracy. The KAPPA coefficient value is 0.8891 .

By using 8-year interval, $400 \mathrm{~m}^{2}$ cellular size, 5 x 5 neighborhood as optimized combination for CA-Markov model to simulate the land use in the 2022, the modelling results are shown in Figure 3-c. The area of Water, grassland, woodland and desert and bare land area variation is changed greatly especially the water's area. Among them, the water, cultivated land, woodland have a decrease trend, and the water's area reduces to $33 \mathrm{~km}^{2}$, while desert and bare land, artificial pile and digging, structures showed increasing trend, and the area of desert and bare surface increases up to $12.67 \mathrm{~km}^{2}$. As you can see from Figure 2-c. Desert and bare land, artificial piling and digging are mostly distributed along the lake shore.

\section{CONCLUSIONS AND DISCUSSIONS}

Based on our experiment, we found that the modelling accuracy is influenced by the cellular size, neighbourhood size and time interval. The modelling accuracy with different scale combinations varies and it turns out that 8 -year interval, $400 \mathrm{~m}^{2}$ cellular size, 5 x 5 neighbourhood is the best scale combination This research, taking advantage of CA - Markov model, GIS and RS technology, analyzes the characteristics and trend of land cover change of Fuxian lake watershed from 2006 to 2014 and predicts the land use spatial pattern of Fuxian watershed in 2022, which can provide scientific evidence for decisionmaking on regional land use planning and protection of ecological environment.

The dynamic changes of area shows that from 2006-2022 the area of water, woodland, cultivated land continues to reduce; the area of building region, artificial piling and digging land mounts up; the grass land increases quickly and these change happens all across the area; the water area reduces drastically; desert, bare surface, artificial piling and digging land area shows an increasing trend and mainly distributes along the lake; garden and roads just change a little. Although the water, forest, cultivated land has decreased, but it is still the main land cover type in the Fuxian lake watershed. The modelling result shows the land use change is dramatic and the land degradation is quite server, and the restoration and reconstruction of Fuxian lake watershed's ecological environment is facing a serious challenge.

\section{ACKNOWLEDGEMENTS}

This research is supported by the demonstrative project "The dynamic monitoring to ecological environment in the lake Fuxian watershed" of National Administration of Surveying, Mapping and Geo-information of China. Thanks to Dr. Yang for providing valuable advice.

\section{REFERENCES}

Balzter, H., Braun, P.W., Kohler, W., 1998. Cellular automata models for vegetation dynamics. Ecol Model, 107, pp.113-125.
Berling, W.S. and Wu, J., 2004. Modeling urban landscape dynamics: A case study in phoenix. USA.Urban Ecosystems. 7(3), pp.215-240.

Cheng, G., Zhang, Z.L., Lv, J.S., 2013. Landscape pattern analysis and dynamic prediction of Sanchuan basin in East China based on CA-Markov model. Chinese Journal of Ecology, 32(4), pp. 999-1005.

Duan, Z.Q., Verburg, P.H., Zhang, F.R., et al., 2004. Construction of a Land-use Change Simulation Model and Its Application in Haidian District, Beijing. Acta Geographica Sinica, 59 (6), pp. 1037-1047.

Eastman, J.R., 2006. IDRISI Andes. Clark University,Worcester, MA.

Gil, R., Pontius, JEFFREY, MALANSON., 2005. Comparison of the structure and accuracy of two land change models. International Journal Geographical Information Science, 19(2), pp.243-265.

Hou, X.Y., Chang, B., Yu, X.F., 2004. Land use change in Hexi corridor based on CA-Markov methods. Transactions of the CSAE, 20 (5), pp.286 -291.

Jenerette, D.G. and Wu, J., 2001. Analysis and simulation of land- use change in the central arizona-phoenix region, USA. Landscape Ecology, 16(7), pp. 611-626.

Ke, X.L., Deng, X.Z., He, S.J., 2010. Scale sensitivity and its causality for Geo-cellular Automata modelling. Geographical Research, 29 (9), pp.863-872.

Li, X., Liu, X.P., 2007. Case based cellular automaton for simulating urban development in a large complex region. Acta Geographica Sinica, 62(10), pp.1097-1109.

Li, X.B., 1996. A review of the international researches on land use/land cover change. Acta Geographica Sinica, 51(3), pp. 553-557.

Liu, X. and Andersson, C., 2004. Assessing the impact of temporal dynamics on land-use change modeling. Computers Environment and Urban Systems, 28(1-2), pp. 107-124.

Menard, A. and Marceau, D.J., 2005. Exploration of spatial scale sensitivity in geographic cellular automata. Environment and Planning B: Planning \& Design, 32(5), pp. 693-714.

Mondal, M.S., Sharma, N., Kappas, M., Garg, P.K., 2012. Modeling of spatio-temporal dynamics of LULC- a review and assessment. J Geom. 6, pp.29-39.

Ouyang, W., Skidmore, A.K., Toxopeus , A.G., et al., 2010. Long-term vegetation landscape pattern with non-point source nutrient pollution in upper stream of Yellow River basin. Journal of Hydrology, 389, pp. 373-380.

Pontius, R.G. and Schneider, L.C., 2001. Land cover change model validation by an ROC method for the Ipswich watershed, Massachusetts, USA. Agriculture Ecosystems and Environment, 85 , pp.239-248. 
Qin, X.H., Duan, X.J., Li, H., et al., 2009. Urban Land Expansion Simulation Model Based on SD and CA-A Case Study of Nantong City. Scientia Geographical Sinica, 29(3), pp.439-444.

Verda, Kocabas., Suzana, Dragicevic., 2006. Assessing cellular automata model behavior using a sensitivity analysis approach. Computers Environment and Urban Systems, 30, pp. 921-953.

Wang, L.P., Jin, X.B., Du, X.D., et al., 2012. Land use scenarios simulation of Foshan city based on gray model and cellular automata model. Transactions of the CSAE, 28 (3), pp.237-242.

Wijesekara, G.N., Gupta, A., Valeo, C., et al., 2012. Assessing the impact of future land-use changes on hydrological processes in the Elbow River watershed in southern Alberta, Canada. Journal of Hydrology, 412/413, pp.220-232.

Xiao, M., Wu, J.Q., Chen, Q.B., et al., 2012. Dynamic change of land use in Changhua downstream watershed based on CAMarkov model. Transactions of the CSAE, 28 (10), pp.231-238.

Yang, G.Q., Liu, Y.L., Wu, Z.F., 2007. Analysis and Simulation of Land-Use Temporal and Spatial Pattern Based on CAMarkov Model. Geomatics and Information Science of Wuhan University, 32(5), pp. 414-418.

Yin, C.L., Zhang, H.H., You, S.J., et al., 2008. Characterizing the spatial scale effect of urban growth cellular automata model. Science of Surveying and Mapping, 33 (5), pp.78-80. 